\title{
Polymorphism of SERPINE2 gene is associated with pulmonary emphysema in consecutive autopsy cases
}

\author{
Koichi Fujimoto ${ }^{1}$, Shinobu Ikeda ${ }^{1}$, Tomio Arai $^{2}$, Noriko Tanaka ${ }^{3}$, Toshio Kumasaka ${ }^{4}$, Takeo Ishii ${ }^{5}$, Kozui Kida ${ }^{5}$, \\ Masaaki Muramatsu ${ }^{1 *}$, Motoji Sawabe ${ }^{2}$
}

\begin{abstract}
Background: The SERPINA1, SERPINA3, and SERPINE2 genes, which encode antiproteases, have been proposed to be susceptible genes for of chronic obstructive pulmonary disease (COPD) and related phenotypes. Whether they are associated with emphysema is not known.

Methods: Twelve previously reported single nucleotide polymorphisms (SNPs) in SERPINA1 (rs8004738, rs17751769, rs709932, rs11832, rs1303, rs28929474, and rs17580), SERPINA3 (rs4934, rs17473, and rs1800463), and SERPINE2 (rs840088 and rs975278) were genotyped in samples obtained from 1,335 consecutive autopsies of elderly Japanese people. The association between these SNPs and the severity of emphysema, as assessed using macroscopic scores, was determined.

Results: Emphysema of more than moderate degree was detected in 189 subjects (14.1\%) and showed a significant gender difference (males, 20.5\% and females, 7.0\%; $p<0.0001$ ). Among the 12 examined SNPs, only rs975278 in the SERPINE2 gene was positively associated with emphysema. Unlike the major alleles, homozygous minor alleles of rs975278 were associated with emphysema (odds ratio $(\mathrm{OR})=1.54 ; 95 \%$ confidence interval $(\mathrm{Cl})=$ 1.02-2.30; $p=0.037)$ and the association was very prominent in smokers $(O R=2.02 ; 95 \% \mathrm{Cl}=1.29-3.15 ; \mathrm{p}=0.002)$.
\end{abstract}

Conclusions: SERPINE2 may be a risk factor for the development of emphysema and its association with emphysema may be stronger in smokers.

\section{Background}

The pathogenesis of chronic obstructive pulmonary disease (COPD) involves both small airway remodeling and emphysema [1]. Pulmonary emphysema is defined through pathological criteria as an "abnormal permanent enlargement of the airspaces distal to the terminal bronchioles, accompanied by destruction of the alveolar walls, and without obvious fibrosis" [2]. Emphysema progression is inextricably linked to the destruction of alveolar elastic fibers by elastolytic proteases associated with a chronic tobacco smoke-induced inflammatory process and to an antiprotease deficiency such as in alpha 1- antitrypsin deficiency [3].

\footnotetext{
* Correspondence: muramatsu.epi@mri.tmd.ac.jp

'Department of Molecular Epidemiology, Medical Research Institute, Tokyo Medical and Dental University, 2-3-10 Kanda-surugadai, Chiyoda-ku, Tokyo 101-0062, Japan

Full list of author information is available at the end of the article
}

Cigarette smoking may induce inflammation in the lungs and increase the release of proteases, which are counteracted by antiproteases in order to prevent parenchymal injury. However, smokers in whom COPD develops, the production of antiproteases may be inadequate to neutralize the effects of multiple proteases, possibly because of genetic polymorphisms that impair the function or production of these proteins [4]. Epidemiologic data indicate that over $95 \%$ of patients with COPD are current or former smokers; however, only about 10-20\% of smokers develop COPD [5,6]. In this regard, additional factors such as genetic variability contribute to smoke susceptibility [7].

Serpins constitute a group of protease inhibitors comprising 36 human proteins [8]. Serpins regulate processes such as coagulation and inflammation by blocking targets of chymotrypsin-like serine proteases such as thrombin, 
trypsin, and human neutrophil elastase. As per the established nomenclature for serpins [9], the human genome encodes 16 clades of serpins-Serpin A through Serpin $\mathrm{P}$-and the corresponding genes are further categorized into 29 inhibitory and 7 non-inhibitory genes [10]. SERPINA1, SERPINA3, and SERPINE2 are reported to be associated with COPD [11-22].

Alpha 1-antitrypsin deficiency is a high risk factor for COPD [11,12] and is associated with rare polymorphisms in the SERPINA1 gene. In fact, studies on common SERPINA1 variants have revealed that SERPINA1 haplotypes are associated with COPD [13], albeit not very conspicuously.

Alpha 1-antichymotrypsin, encoded by SERPINA3, is a plasma protease inhibitor that targets neutrophil cathepsin $\mathrm{G}$ and elastase [14]. In several cases, mutations in SERPINA3 are found to be associated with COPD [15]. A similar but less prominent association is found between COPD and common variants of SERPINA3 [16-18].

SERPINE2 encodes protease nexin 1-the archetypal member of the serine protease inhibitor family. DeMeo and associates first suggested that SERPINE2 is a COPD susceptibility gene and is probably influenced by a geneby-smoking interaction in the Boston Early-Onset COPD study [19]. Subsequently, this was further validated and supported by additional data [20-22].

Although a number of large population studies are reported for COPD, few studies are well reproduced, probably due to the heterogenous mixture of COPD phenotypes. As COPD is composed of at least two components, the examination of emphysema might reduce the heterogeneity, and provide insight into specific mechanisms associated with mortality. In this study, we investigated 12 putative causal SNPs in SERPINA1, SERPINA3, and SERPINE2 by using autopsy samples obtained from 1,335 consecutive Japanese individuals. We then studied the association between these SNPs and emphysema, which was categorized on the basis of macroscopic scores.

\section{Methods}

\section{Subject population}

From February, 1995 to July, 2003, 1,536 autopsies were performed at the Department of Pathology, Tokyo Metropolitan Geriatric Medical Center, Tokyo, Japan. Of these, 1,335 (717 males and 618 females) were performed on Japanese cadavers, and the pathological findings of the lungs obtained during these autopsies were used in this study. The characteristics of the study population are available at an Internet-based database called "The Japanese SNP database for geriatric research (JG-SNP)" http://www.tmghig.jp/jg-snp/english/E_top.html.
Smoking status of the individuals was retrospectively determined by reviewing medical records, and subjects were classified as smokers (including ex-smokers) and life-time never-smokers. No medico-legal cases were included in the study. We did not use data from lungfunction tests for association analysis because limited data were available, and because the duration between the conduction of these tests and death varied widely.

\section{Pathological assessment of emphysema}

Both excised lungs were inflated with a $10 \%$ formalin solution at a constant pressure of $25 \mathrm{~cm} \mathrm{H} \mathrm{H}_{2} \mathrm{O}$. The lungs were section in the sagittal plane to obtained 2-cm-thick slices.

The type and severity of the emphysematous changes in all the lung slices were macroscopically assessed by a pulmonary pathologist (K.T.). Emphysema was classified as centrilobular emphysema (CE), panlobular emphysema (PE), or focal emphysema (FE), and its severity was scored on a scale of 0-4 for each slice, by using a previously described method $[2,23]$, where $0=$ no changes, 1 = minimal changes, $2=$ mild changes, $3=$ moderate changes, and $4=$ severe changes. The mean scores for slices from both lungs were used in an association analysis of single nucleotide polymorphisms (SNPs) (see below). In this study, emphysema was defined as CE changes with a score of $>2$ and/or PE changes with a score of $\geq 1$, since $C E$ changes are known to be mainly caused by smoking, and PE with $\mathrm{CE}$ is considered an extension of severe CE [24]. Patients whose emphysema scores for both lungs differed by more than 2 points were excluded from the study, because in general, the bilateral severity of the emphysema is closely correlated [24], and such wide differences might have been due to additional unusual effects.

\section{SNP selection}

We selected 7 SERPINA1 SNPs (rs8004738, rs17751769, rs709932, rs11832, rs1303, rs28929474, and rs17580), 3 SERPINA3 SNPs (rs4934, rs17473, and rs1800463), and 2 SERPINE2 SNPs (rs840088 and rs975278) by referring to previous studies on COPD phenotypes $[13,15,16,19,20]$. The SNPs whose minor allele frequencies (MAFs) in the Japanese population were found to be less than 0.1 in the HapMap project http://hapmap.ncbi.nlm.nih.gov/ were excluded from this study. One of the SERPINE2 SNPs (rs840088; intron 1) has been reported to be associated with COPD in both family and case-control studies [19], and the other (rs975278; intron 5) has been reported to be associated with COPD phenotypes in 2 large populations [20]. We also screened for the PiS variant (rs17580) and PiZ variant (rs28929474), which are known to be the 
most common variants associated with alpha 1-antitrypsin deficiency $[25,26]$.

\section{Genotyping}

Genomic DNA was extracted from the renal cortex by the phenol-chloroform method and stored at $-20^{\circ} \mathrm{C}$ until use. For genotype analysis, 10-ng aliquots of DNA were introduced into 384-well polymerase chain reaction (PCR) plates by using an automated fluid dispenser (BioMek2000; Beckman Coulter Inc., Fullerton, CA) and dried in a dry chamber.

Two SERPINE2 SNPs (rs840088 and rs975278) and one SERPINA1 SNP (rs1303) were genotyped using Taqman 5'-exonuclease assays, with primers obtained from Applied Biosystems Inc. (Foster City, CA). Major and minor allele probes were labeled with different colored fluorophores, and the fluorescence signals were detected using the ABI Prism 7900HT sequence detector system. The remaining 9 SNPs were genotyped using a melting curve analysis on a LightCycler 480 system (Roche Diagnostics K. K., Tokyo, Japan). Pathological assessments and genotyping were performed at different facilities in a double-blind manner. The PCR primers and hybridization probes used for the melting curve analysis are listed in additional file 1, table S1.

\section{Ethical considerations}

All the autopsies and subsequent medical and genetic studies were performed with the written informed consent of the bereaved family of each patient. The use of autopsy materials for medical education and research is generally permitted by the Act of Postmortem Examinations of Japan. This study was approved by the ethics committees of Tokyo Metropolitan Geriatric Medical Center and Tokyo Medical and Dental University.

\section{Statistical analysis}

Allelic test and genotype test in recessive model were used to detect the genetic contributions. Statistical analysis was performed using SAS ver. 9.1.3 (SAS Institute Inc., Cary, NC). Multiple logistic regression analyses were performed to examine the emphysema-related differences in the patients' clinical backgrounds and to calculate the odds ratio (ORs) and 95\% confidence intervals (CIs). The estimates were adjusted for gender, age at the time of death, and smoking status. The Hardy-Weinberg equilibrium for all SNPs was tested using the chi-square goodness-of-fit test. Haplotype analyses of 5 SNPs (rs8004738, rs17751769, rs709932, rs11832, and rs1303) were performed using the stochastic expectation-maximization (EM) algorithm, which is incorporated in the THESIAS program http://ecgene. net/genecanvas/uploads/THESIAS3.1/Documentation3.1. htm. A p value of $<0.05$ was considered statistically significant. The $\mathrm{p}$ values have not been adjusted for multiple testing.

\section{Results \\ Study participants}

The baseline characteristics of the subjects are shown in Table 1. The mean age at the time of death was 80.1 years. Of the 1355 subjects, 99 (7.4\%) had CE with minimal changes, 248 (18.6\%) had mild changes, 156 patients (11.7\%) had moderate changes, 28 patients $(2.1 \%)$ had severe changes, and the remaining 804 patients $(60.2 \%)$ had no detectable emphysema. The pathological diagnosis of emphysema, which was defined as previously described, was made on $14.2 \%$ of the subjects $(n=189)$. Emphysema was more common among men than among women $(20.5 \%$ vs. $7 \%$; p < 0.0001). Further, $47.1 \%$ of the study population had a history of smoking, with a significant gender difference (males vs. females; $69.6 \%$ vs. $21.0 \%$; $\mathrm{p}<0.0001$ ). Smoking was found to be a significant risk factor for the development of emphysema in the total study population $(\mathrm{OR}=4.45,95 \%$ $\mathrm{CI}=2.88-7.06 ; \mathrm{p}<0.0001)$, and posed a slightly higher risk in women $(\mathrm{OR}=5.22,95 \% \mathrm{CI}=2.59-10.70 ; \mathrm{p}<$ $0.0001)$ than in men $(\mathrm{OR}=4.14,95 \% \mathrm{CI}=2.40-7.65$; $\mathrm{p}<0.0001)$.

\section{Association between genetic polymorphisms of candidate genes and emphysema}

The distribution of the 12 SNP genotypes and their association with emphysema are shown in Table 2. Neither the PiZ and PiS variants (rs28929474 and rs17580 respectively) nor the 2 reportedly rare variants of SERPINA3 (rs17473 and rs1800463) were detected in any of the samples examined. The MAFs obtained in our analysis did not considerably deviate from the data obtained in the HapMap project http://hapmap.ncbi.nlm.nih.gov/. The distribution of all genotypes did not significantly deviate from the Hardy-Weinberg equilibrium.

Subjects with and without emphysema did not show any differences in the genotypic distribution of $5 S E R$ PINA1 SNPs and 1 SERPINA3 SNP. However, significant differences were found in the genotypic distribution of 1 SERPINE2 SNP (rs975278). This SNP was significantly associated with emphysema $(\mathrm{OR}=1.54,95 \% \mathrm{CI}=1.02$ 2.30; $\mathrm{p}=0.037$ )

\section{Association of the SERPINE2 SNP rs975278 and smoking with emphysema}

We next examined whether the effects of rs975278 differed between smokers and non-smokers. Among the smokers, the allelic and genotypic frequencies of this SNP were significantly different between subjects with and without emphysema (Table 3). A high frequency of GG homozygosity was significantly associated with an 
Table 1 Clinical characteristics of the cases

\begin{tabular}{lllll}
\hline & $\begin{array}{l}\text { Total (\%) } \\
\mathbf{N}=\mathbf{1 3 3 5}\end{array}$ & $\begin{array}{l}\text { Subjects with emphysema (\%) } \\
\mathbf{N}=\mathbf{1 8 9}\end{array}$ & $\begin{array}{l}\text { Subjects without emphysema (\%) } \\
\mathbf{N}=1 \mathbf{1 4 6}\end{array}$ & $\mathbf{p}$ values \\
\hline Men (\%) & $717(53.7 \%)$ & $147(77.8 \%)$ & $570(49.7 \%)$ & $<0.0001^{*}$ \\
Age (years) & $80.1 \pm 9.0$ & $81.3 \pm 7.3$ & $79.9 \pm 9.3$ & $<0.0001^{\dagger}$ \\
History of smoking & & & $483(42.1 \%)$ & $<0.0001^{\ddagger}$ \\
$\quad$ Smokers & $629(47.1 \%)$ & $146(77.2 \%)$ & $578(50.4 \%)$ & $85(7.4 \%)$ \\
$\quad$ Non-smokers & $610(45.7 \%)$ & $32(16.9 \%)$ & $17.7 \pm 31.9$ & $<0.0001^{\ddagger}$ \\
$\quad$ Data not available & $96(7.2 \%)$ & $11(5.8 \%)$ & & \\
$\quad$ Pack-years & $21.2 \pm 36.3$ & $45.0 \pm 40.5$ & & \\
\hline
\end{tabular}

*Multiple logistic regression analysis adjusted for age and smoking history. †Multiple logistic regression analysis adjusted for sex and smoking history. ¥Multiple logistic regression analysis adjusted for age and sex.

increased OR for emphysema $(\mathrm{OR}=2.02,95 \% \mathrm{CI}=$ 1.29-3.15; $\mathrm{p}=0.002$ ).

We performed haplotype analyses for 5 adjacent SERPINA1 SNPs, but none of the haplotypes was found to be associated with emphysema (data not shown).

\section{Discussion}

The present study revealed that a polymorphism in SERPINE2 (rs975278) was associated with emphysema in consecutive autopsies of Japanese subjects. In the total study population, the OR for minor allele homozygotes was 1.54 (95\% CI = 1.02-2.30). Among smokers, the OR for minor allele homozygotes was 2.02 (95\% CI $=1.29$ $3.15)$. If the $\mathrm{p}$ values are corrected with multiple testing of twelve SNPs, the data without smoking stratification does not show any statistical significance. Among the smokers, however, the differences of the allelic and genotypic frequencies between subjects with and without emphysema were significant ( $p$ value $\times 12<0.05$ ). To our knowledge, this is the first study to report that a
SERPINE2 variant is closely associated with emphysema, especially in smokers.

\section{SERPINE2}

SERPINE2 encodes a 44-kDa cellular and extracellular matrix-associated serine protease inhibitor [27], which is expressed in the developing and adult lung as well as in the airway epithelial cells [19]. The SERPINE2 protein mainly functions in coagulation and fibrinolysis by inhibiting thrombin, urokinase, and plasmin $[27,28]$. Plasmin is capable of contributing to metalloproteinase activation [29], thus, SERPINE2 may play an important role in lung physiology [30].

SERPINE2 was initially identified as a positional candidate for COPD and related phenotypes on chromosome 2q33-35 [31]. Subsequently the association of SNPs in SERPINE2 with COPD was observed in a case-control study in smokers [19]. Three independent groups attempted to replicate the findings of the above study: one study successfully replicated the association [20],

Table 2 Association of 12 SNPs with emphysema

\begin{tabular}{|c|c|c|c|c|c|c|}
\hline Gene and SNP & Allele & $\begin{array}{l}\text { Genotypic frequency in subjects } \\
\text { with emphysema } \\
\text { (n = 189) } \\
\mathrm{MM} / \mathrm{Mm} / \mathrm{mm}\end{array}$ & $\begin{array}{l}\text { Genotypic frequency in subjects } \\
\text { without emphysema } \\
\text { (n = 1146) } \\
\mathrm{MM} / \mathrm{Mm} / \mathrm{mm}\end{array}$ & $\begin{array}{l}p \text { value } \\
\text { for } \\
\text { HWE }\end{array}$ & $\begin{array}{l}\mathrm{p} \text { value for } \\
\text { minor allele } \\
\text { carriers* }\end{array}$ & $\begin{array}{l}p \text { value for } \\
\text { minor allele } \\
\text { homozygotes* }\end{array}$ \\
\hline \multicolumn{7}{|l|}{ SERPINA1 } \\
\hline rs8004738 & $A / G$ & $.26 / .50 / .24$ & $.24 / .51 / .25$ & .873 & .761 & .459 \\
\hline rs17751769 & $A / G$ & $.26 / .50 / .24$ & $.24 / .50 / .26$ & .858 & .902 & .573 \\
\hline rs709932 & $G / A$ & $.53 / .40 / .07$ & $.56 / .37 / .07$ & .450 & .439 & .866 \\
\hline rs1303 & $\mathrm{A} / \mathrm{C}$ & $.47 / .42 / .11$ & $.51 / .40 / .09$ & .896 & .275 & .572 \\
\hline rs11832 & $A / G$ & $.45 / .42 / .13$ & $.49 / .40 / .11$ & .148 & .217 & .416 \\
\hline \multicolumn{7}{|l|}{ SERPINA3 } \\
\hline rs4934 & $A / G$ & $.37 / .44 / .19$ & $.35 / .47 / .18$ & .440 & .699 & .910 \\
\hline \multicolumn{7}{|l|}{ SERPINE2 } \\
\hline rs840088 & $\mathrm{C} / \mathrm{T}$ & $.32 / .49 / .19$ & $.35 / .48 / .17$ & .928 & .699 & .908 \\
\hline rs975278 & $A / G$ & $.26 / .47 / .27$ & $.29 / .52 / .19$ & .329 & .175 & .037 \\
\hline
\end{tabular}

*Multiple logistic regression analysis adjusted for age, sex, and smoking history.

Statistically significant values $(p<0.05)$ are shown in boldface.

$p$ values shown above have not been adjusted for multiple testing.

Abbreviations: MM, major allele homozygote; Mm, heterozygote; mm, minor allele homozygote; HWE, Hardy-Weinberg equilibrium. 
Table 3 Association of rs975278 with emphysema in smokers

\begin{tabular}{cllll}
\hline Variables & $\begin{array}{l}\text { Subjects with emphysema } \\
(\mathbf{n}=\mathbf{1 2 7})\end{array}$ & $\begin{array}{l}\text { Subjects without emphysema } \\
(\mathbf{n}=\mathbf{4 2 5})\end{array}$ & p value* & Odds ratio (95\%)* \\
\hline $\begin{array}{l}\text { Genotype } \\
\text { GG }\end{array}$ & $42(33 \%)$ & $83(20 \%)$ & $\mathbf{0 0 2}$ & $\mathbf{2 . 0 2 ( 1 . 2 9 - 3 . 1 5 )}$ \\
AG+AA & $85(67 \%)$ & $342(80 \%)$ & & $\mathbf{2 . 6 1 ( 1 . 4 5 - 4 . 7 6 )}$ \\
Allele & & & .001 & \\
G & 0.57 & 0.45 & & \\
A & 0.43 & 0.55 &
\end{tabular}

*Multiple logistic regression analysis adjusted for age and sex.

while the others did not [32,33]. Further, SERPINE2 polymorphisms were used to study COPD-related phenotypes; association with hypoxemia with severe COPD [34] and with bronchodilator responsiveness in COPD [35] were observed. Thus, accumulating evidence shows that SERPINE2 is a susceptible gene of COPD and a modifier of COPD related phenotypes, but its relation with emphysema remains unknown. Our finding that SERPINE2 polymorphism is associated with emphysema appears to be consistent with the findings of these previous studies that reported positive associations [19,20], as assessed using physiological parameters of lung function. According to the Hapmap project, the allele frequencies of the polymorphism (rs975278) are different in population groups, however, the risk allele ( $G$ allele) pointed to the same direction in the present study. These previous findings were further explored in our study, which analyzed pathological findings in consecutive autopsy cases.

In this study, the association of SERPINE2 polymorphism with emphysema was more prominent among the smokers. This suggests that SERPINE2 variants contribute to the risk of developing emphysema in smokers. While the reason for this interaction is presently unclear, many smoking-associated genes have been identified [36]. It is tempting to speculate that SERPINE2 polymorphism may affect SERPIMI2 expression after exposure to cigarette smoke and may thus hamper the repair of smoking-induced lung damage. However, the mechanism by which SERPINE2 contributes to the development of emphysema remains to be elucidated.

We also examined whether the variants studied were associated with the typical complications related to COPD, including osteoporosis, aortic aneurysm, myocardial infarction, aortic dissection, cerebral infarction, intracranial hemorrhage, and interstitial pneumonitis. Our results in this regard were negative (data not shown).

\section{Emphysema and COPD}

COPD is a clinical condition that is diagnosed by physiological tests, whereas pulmonary emphysema is diagnosed by pathological examinations. Although these conditions are not identical, both are indicative of a disease involving airway obstruction and chronic bronchitis. An important feature of our study is that we performed pathological examinations to evaluate the disease phenotype; such analysis is usually not possible in routine clinical practice. The genetic contribution we investigated for emphysema may be more reflecting the final steps of the COPD that involve severe alveolar damage due to imbalance of proteaseses and their inhibitors.

With the recent advancements in computed tomography $(\mathrm{CT})$, high-resolution images that enable a reasonably accurate assessment of pulmonary emphysema can be obtained [37]. Emphysema appears to be correlated with the severity of lung function impairment in COPD [38]; however, attempts have been made to categorize COPD, regardless of whether emphysema is detected using CT. Some candidate gene polymorphisms are reported to be associated with emphysema, as diagnosed using CT [39-41]. We believe that SERPINE2 is a good candidate gene that is associated with emphysema, as diagnosed using CT.

Thus, our finding that a SERPINE2 variant is associated with emphysema may indicate that this variant influences the severity of lung destruction rather than the presence or absence of chronic pulmonary obstruction. Future studies should aim to elucidate the genetic background of COPD with and without pulmonary emphysema.

\section{Limitations}

Spirometric data were not sufficiently available in this study since the samples were obtained during autopsies of elderly subjects. Small number of subjects, especially only 32 non-smoker patients have pulmonary emphysema, may reduce power to detect genetic associations. The present study included only those individuals who underwent autopsy and had an average age with emphysema was similar to those without emphysema (Table 1). This implies that the study population may have been skewed towards individuals with mild disease, and that a 
survival bias may have been present. The elderly population is likely to be exposed to long-term environmental effects other than smoking; however, the present study did not consider these effects.

\section{Conclusions}

The present study revealed that a SERPINE2 SNP (rs975278) was associated with pathologically diagnosed emphysema in consecutive autopsies of Japanese smokers. Further studies are required to clarify the molecular and biochemical mechanisms underlying this association.

\section{Additional material}

Additional table S1: Primers and probes used for genotyping. The

PCR primers and hybridization probes used for the melting curve analysis.

\section{Acknowledgements}

This study was supported by the Joint Usage/Research Program of Medical Research Institute, Tokyo Medical and Dental University. This study was concepted and designed by K.F., T. I. and M.M. Data acquisition was done by T.A, and M.S, Analysis was done by S.I., N.T, drafting and revising the manuscript was done by K.F and M. M, interpretation of the data and critical reading of the manuscript was done by $T$. K. and $K$. K. This study was supported by the Joint Usage/Research, Program of Medical Research Institute, Tokyo Medical and Dental University.

\section{Author details}

'Department of Molecular Epidemiology, Medical Research Institute, Tokyo Medical and Dental University, 2-3-10 Kanda-surugadai, Chiyoda-ku, Tokyo 101-0062, Japan. ${ }^{2}$ Department of Pathology, Tokyo Metropolitan Geriatric Hospital, 35-2 Sakae-cho, Itabashi-ku, Tokyo 173-0015, Japan. ${ }^{3}$ Department of Biostatistics, Harvard School of Public Health, Boston, MA, USA. ${ }^{4}$ Department of Pathology, Juntendo University School of Medicine, 2-1-1 Hongo, Bunkyo-ku, Tokyo 113-8421, Japan. ${ }^{5}$ Department of Pulmonary Medicine, Infection and Oncology, Nippon Medical School, 1-1-5 Sendagi, Bunkyo-ku, Tokyo 113-8602, Japan.

\section{Authors' contributions}

SI performed the SNP genotyping; TA prepared the clinicopathological data; NT conducted the statistical analysis; TK assessed the lung pathology; TI and KK reviewed the manuscript; MM provided general instructions on SNP genotyping and manuscript writing; and MS prepared the clinicopathological data and provided general instructions on the study. All authors read and approved the final manuscript.

\section{Competing interests}

This study was supported in part by a grant from the Smoking Research Foundation to M.S., Tokyo, Japan.

Received: 23 February 2010 Accepted: 10 November 2010 Published: 10 November 2010

\section{References}

1. Rabe KF, Hurd S, Anzueto A, Barnes PJ, Buist SA, Calverley P, Fukuchi Y, Jenkins C, Rodriguez-Roisin R, van Weel C, Zielinski J: Global strategy for the diagnosis, management, and prevention of chronic obstructive pulmonary disease: GOLD executive summary. Am J Respir Crit Care Med 2007, 176:532-555

2. Report of a National Heart, Lung, and Blood Institute, Division of Lung Diseases workshop: The definition of emphysema. Am Rev Respir Dis 1985, 132:182-5.
3. Barnes PJ: Chronic obstructive pulmonary disease. N Engl J Med 2000, 343:269-280.

4. Stockley RA: Neutrophils and protease/antiprotease imbalance. Am J Respir Crit Care Med 1999, 160:S49-52.

5. American Thoracic Society: Cigarette smoking and health. Am J Respir Crit Care Med 1996, 153:861-5.

6. Fletcher $\mathrm{C}$, Peto R: The natural history of chronic airflow obstruction. $\mathrm{Br}$ Med J 1977, 1:1645-1648.

7. Sandford AJ, Silverman EK: Chronic obstructive pulmonary disease. 1: Susceptibility factors for COPD the genotype-environment interaction. Thorax 2002, 57:736-41.

8. Irving JA, Pike RN, Lesk AM, Whisstock JC: Phylogeny of the serpin superfamily: implications of patterns of amino acid conservation for structure and function. Genome Res 2000, 10:1845-64.

9. Silverman GA, Bird PI, Carrell RW, Church FC, Coughlin PB, Gettins PG, Irving JA, Lomas DA, Luke CJ, Moyer RW, Pemberton PA, RemoldO'Donnell E, Salvesen GS, Travis J, Whisstock JC: The serpins are an expanding superfamily of structurally similar but functionally diverse proteins. Evolution, mechanism of inhibition, novel functions, and a revised nomenclature. J Biol Chem 2001, 276:33293-6.

10. Law RH, Zhang Q, McGowan S, Buckle AM, Silverman GA, Wong W, Rosado CJ, Langendorf CG, Pike RN, Bird PI, Whisstock JC: An overview of the serpin superfamily. Genome Biol 2006, 7(216):1.

11. DeMeo DL, Silverman EK: Alpha1-antitrypsin deficiency. 2: genetic aspects of alpha(1)-antitrypsin deficiency: phenotypes and genetic modifiers of emphysema risk. Thorax 2004, 59:259-64.

12. Hersh CP, Dahl M, Ly NP, Berkey CS, Nordestgaard BG, Silverman EK: Chronic obstructive pulmonary disease in alpha1-antitrypsin PI MZ heterozygotes: a meta-analysis. Thorax 2004, 59:843-84.

13. Chappell S, Daly L, Morgan K, Guetta Baranes T, Roca J, Rabinovich R, Millar A, Donnelly SC, Keatings V, MacNee W, Stolk J, Hiemstra P, Miniati M, Monti S, O'Connor M, Kalsheker N: Cryptic haplotypes of SERPINA1 confer susceptibility to chronic obstructive pulmonary disease. Hum Mutat 2006, 27:103-109.

14. Nagareda T, Takeda M, Kojima K, Tanaka A, Terada N, Yamasaki T, Nagareda T, Ueno H, Kotoh K: Alpha-1 antichymotrypsin is increased in human alveolar macrophages by phorbol myristate acetate or lipopolysaccharide and released from these activated macrophages by glucocorticoid. J Pathol 1991, 165:319-23.

15. Poller W, Faber JP, Weidinger S, Tief K, Scholz S, Fischer M, Olek K Kirchgesser M, Heidtmann $\mathrm{HH}$ : A leucine-to-proline substitution causes a defective alpha 1-antichymotrypsin allele associated with familial obstructive lung disease. Genomics 1993, 17:740-743.

16. Ishii T, Matsuse T, Teramoto S, Matsui H, Hosoi T, Fukuchi Y, Ouchi Y: Association between alpha-1-antichymotrypsin polymorphism and susceptibility to chronic obstructive pulmonary disease. Eur J Clin Invest 2000, 30:543-548.

17. Benetazzo MG, Gilè LS, Bombieri C, Malerba G, Massobrio M, Pignatti PF, Luisetti M: Alpha 1-antitrypsin TAQ I polymorphism and alpha 1antichymotrypsin mutations in patients with obstructive pulmonary disease. Respir Med 1999, 93:648-54

18. Hersh CP, Demeo DL, Lange C, Litonjua AA, Reilly JJ, Kwiatkowski D, Laird N, Sylvia JS, Sparrow D, Speizer FE, Weiss ST, Silverman EK: Attempted replication of reported chronic obstructive pulmonary disease candidate gene associations. Am J Respir Cell Mol Biol 2005, 33:71-8.

19. DeMeo DL, Mariani TJ, Lange C, Srisuma S, Litonjua AA, Celedon JC, Lake SL, Reilly JJ, Chapman HA, Mecham BH, Haley KJ, Sylvia JS, Sparrow D, Spira AE, Beane J, Pinto-Plata V, Speizer FE, Shapiro SD, Weiss ST, Silverman EK: The SERPINE2 gene is associated with chronic obstructive pulmonary disease. Am J Hum Genet 2006, 78:253-64.

20. Zhu G, Warren L, Aponte J, Gulsvik A, Bakke P, Anderson WH, Lomas DA, Silverman EK, Pillai SG: International COPD Genetics Network (ICGN) Investigators. The SERPINE2 gene is associated with chronic obstructive pulmonary disease in two large populations. Am J Respir Crit Care Med 2007, 176:167-73.

21. Wang IM, Stepaniants S, Boie Y, Mortimer JR, Kennedy B, Elliott M, Hayashi S, Loy L, Coulter S, Cervino S, Harris J, Thornton M, Raubertas R, Roberts C, Hogg JC, Crackower M, O'Neill G, Paré PD: Gene expression profiling in patients with chronic obstructive pulmonary disease and lung cancer. Am J Respir Crit Care Med 2008, 177:402-11. 
22. Demeo DL, Campbell EJ, Barker AF, Brantly ML, Eden E, McElvaney NG, Rennard SI, Sandhaus RA, Stocks JM, Stoller JK, Strange C, Turino G, Silverman EK: IL10 polymorphisms are associated with airflow obstruction in severe alpha1-antitrypsin deficiency. Am J Respir Cell Mol Biol 2008, 38:114-20.

23. Yamanaka A: Morphopathology of chronic pulmonary emphysema. Acta Pathol Jpn 1965, 15:33-9.

24. Thurlbeck MWilliam: Chronic airflow obstruction. In: Thurlbeck's Pathology of the Lung. Third edition. In Thieme. Edited by: Andrew M Churg, Jeffrey L Myers, Henry D Tazelaar, Joanne L Wright. New York; 2005:675-742.

25. de Serres FJ: Worldwide racial and ethnic distribution of alpha1antitrypsin deficiency: summary of an analysis of published genetic epidemiologic surveys. Chest 2002, 122:1818-29.

26. Luisetti M, Seersholm N: Alpha1-antitrypsin deficiency. 1: epidemiology of alpha1-antitrypsin deficiency. Thorax 2004, 59:164-9.

27. Baker JB, Low DA, Simmer RL, Cunningham DD: Protease-nexin: a cellular component that links thrombin and plasminogen activator and mediates their binding to cells. Cell 1980, 21:37-45.

28. Scott RW, Bergman BL, Bajpai A, Hersh RT, Rodriguez H, Jones BN, Barreda C, Watts S, Baker JB: Protease nexin. Properties and a modified purification procedure. J Biol Chem 1985, 260:7029-34.

29. Lijnen HR, Silence J, Lemmens G, Frederix L, Collen D: Regulation of gelatinase activity in mice with targeted inactivation of components of the plasminogen/plasmin system. Thromb Haemost 1998, 79:1171-6.

30. Joos L, He JQ, Shepherdson MB, Connett JE, Anthonisen NR, Paré PD, Sandford AJ: The role of matrix metalloproteinase polymorphisms in the rate of decline in lung function. Hum Mol Genet 2002, 11:569-76.

31. Silverman EK, Palmer LJ, Mosley JD, Barth M, Senter JM, Brown A, Drazen JM, Kwiatkowski DJ, Chapman HA, Campbell EJ, Province MA, Rao DC, Reilly JJ, Ginns LC, Speizer FE, Weiss ST: Genomewide linkage analysis of quantitative spirometric phenotypes in severe early-onset chronic obstructive pulmonary disease. Am J Hum Genet 2002, 70:1229-39.

32. Chappell S, Daly L, Morgan K, Baranes TG, Roca J, Rabinovich R, Millar A, Donnelly SC, Keatings V, MacNee W, Stolk J, Hiemstra PS, Miniati M, Monti S, O'Connor CM, Kalsheker N: The SERPINE2 gene and chronic obstructive pulmonary disease. Am J Hum Genet 2006, 79:184-6, author reply 186-7.

33. Zhong L, Fu WP, Sun C, Dai LM, Zhang YP: Absence of association between SERPINE2 genetic polymorphisms and chronic obstructive pulmonary disease in Han Chinese: a case-control cohort study. BMC Med Genet 2009, 10:66.

34. Castaldi PJ, Hersh CP, Reilly JJ, Silverman EK: p-7: Genetic associations with hypoxemia and pulmonary arterial pressure in COPD. Chest 2009, 135:737-44.

35. Kim WJ, Hersh CP, DeMeo DL, Reilly JJ, Silverman EK: Genetic association analysis of COPD candidate genes with bronchodilator responsiveness. Respir Med 2009, 103:552-736.

36. Halappanavar S, Stampfli MR, Berndt-Weis L, Williams A, Douglas GR, Yauk CL: Toxicogenomic analysis of mainstream tobacco smoke-exposed mice reveals repression of plasminogen activator inhibitor-1 gene in heart. Inhal Toxicol 2009, 21:78-85.

37. Madani A, Keyzer C, Gevenois PA: Quantitative computed tomography assessment of lung structure and function in pulmonary emphysema. Eur Respir J 2001, 18:720-30.

38. Makita H, Nasuhara $Y$, Nagai K, Ito $Y$, Hasegawa M, Betsuyaku T, Onodera $Y$, Hizawa N, Nishimura M, Hokkaido COPD Cohort Study Group: Characterisation of phenotypes based on severity of emphysema in chronic obstructive pulmonary disease. Thorax 2007, 62:932-739.

39. Takeyabu K, Yamaguchi E, Suzuki I, Nishimura M, Hizawa N, Kamakami Y: Gene polymorphism for microsomal epoxide hydrolase and susceptibility to emphysema in a Japanese population. Eur Respir J 2000, 15:891-4.

40. Ito M, Hanaoka M, Droma Y, Hatayama O, Sato E, Katsuyama Y, Fujimoto K, Ota M: The association of transforming growth factor beta 1 gene polymorphisms with the emphysema phenotype of COPD in Japanese. Intern Med 2008, 47:1387-94.

41. Ito I, Nagai S, Handa T, Muro S, Hirai T, Tsukino M, Mishima M: Matrix metalloproteinase-9 promoter polymorphism associated with upper lung dominant emphysema. Am J Respir Crit Care Med 2005, 172:1378-82.

\section{Pre-publication history}

The pre-publication history for this paper can be accessed here: http://www.biomedcentral.com/1471-2350/11/159/prepub

doi:10.1186/1471-2350-11-159

Cite this article as: Fujimoto et al:: Polymorphism of SERPINE2 gene is associated with pulmonary emphysema in consecutive autopsy cases. BMC Medical Genetics 2010 11:159.

\section{Submit your next manuscript to BioMed Central and take full advantage of:}

- Convenient online submission

- Thorough peer review

- No space constraints or color figure charges

- Immediate publication on acceptance

- Inclusion in PubMed, CAS, Scopus and Google Scholar

- Research which is freely available for redistribution

Submit your manuscript at www.biomedcentral.com/submit
C Biomed Central 